УДК 811.134.2

ББК 81.472.1

DOI: https://doi.org/10.17308/lic.2020.1/2730

\title{
ИНФИНИТИВНЫЕ ПРЕДЛОЖЕНИЯ В РУССКОМ И ИСПАНСКОМ ЯЗЫКАХ
}

\author{
B. В. Корнева \\ Воронежский государственный университет

\section{INFINITIVE SENTENCES \\ IN THE RUSSIAN AND SPANISH LANGUAGES}

\author{
V. V. Korneva \\ Voronezh State University
}

\begin{abstract}
Аннотация: в статье рассматриваются структурно-семантические особенности предложений с независимым инфинитивом в русском и испанском языках. Выявляется их место в системе средств выражения побуждения, вскрываются причины эксплицитности/имплицитности адресата волеизъявления, анализируются лингвистические и экстралингвистические факторы, влияющие на степень развернутости структуры инфинитивных предложений и их семантику, описываются контекстные условия их использования, делаются выводы о функииональном потенциале инфинитива как субституте других глагольных форм в русском и испанском языках и о сходстве и различиях изучаемых конструкций $в$ сравниваемых языках.

Ключевые слова: инфинитивное предложение, независимый инфинитив, побуждение, адресат волеизъявения, имплицитность, эксплицитность, функичиональный субститут, русский язык, испанский языкк.
\end{abstract}

Abstract: the article deals with the semantic characteristics of independent infinitive sentences in Russian and Spanish. The author defines their position in the system of means expressing incentiveness; affecting the degree of infinitive sentence structure's development. Contextual conditions of these sentences use are also described. The author makes a conclusion about the infinitive's functional potential as another verb form's substitute in Russian and Spanish.

Key words: infinitive sentence, independent infinitive, incentiveness, volitions addressee, implicitness, explicitness, functional substitute, Russian, Spanish.

Инфинитивные предложения как определенный тип односоставных предложений, главным членом которых является независимый инфинитив, давно привлекают внимание ученых (см., например, [1-3]). История их изучения в отечественной и зарубежной лингвистике связана с именами таких выдающихся ученых, как А. М. Пешковский, А. А. Шахматов, К. М. Тимофеев, Е. М. Галкина-Федорук, В. В. Виноградов, Мейер Любке, С. Хили-и-Гайя, Э. Аларкос Льорах, Э. Мартинес Амадор, И. Боске и др. Тем не менее и в русистике, и в испанистике продолжаются споры о семантико-синтаксических свойствах инфинитивных предложений (см., например, [4-8 и др.]).
Одна из причин повышенного внимания ученых к данному грамматическому явлению заключается в том, что разнообразные значения, присущие инфинитивным предложениям, не находят экплицитного выражения. А. М. Ломов отмечает необычность семантико-функциональной модели, лежащей в основе инфинитивных предложений, а также нестандартный характер их формального выражения [9, с. 112]. На «нестандартный характер формального механизма» инфинитивных предложений указывают многие ученые. Однако их мнения относительно структурной основы данных предложений значительно расходятся. В частности, авторы «Русской грамматики» счи-

(C) Корнева В. В., 2020

Контент доступен под лицензией Creative Commons Attribution 4.0 License.

The content is available under Creative Commons Attribution 4.0 License. 
тают, что в русском языке она представлена только одним словом - инфинитивом [5, с. 376], тогда как другие ученые утверждают, что в нее также входит существительное в дательном падеже [4, с. 249; 10 , c. $104 ; 11$, c. 149$]$.

Еще большие разногласия наблюдаются при описании семантики инфинитивных предложений. Одни ученые выделяют в них четыре семантических варианта (см., например, [6]), другие - более восьми [5; 10]. При этом все сходятся в том, что инфинитивные предложения выражают значение побуждения (см., например, $[1 ; 2 ; 5 ; 6 ; 8 ; 10 ; 12-14])$. Сказанное свидетельствует о необходимости дальнейшего изучения инфинитивных предложений.

Целью нашего исследования является выявление формальных и семантических особенностей инфинитивных предложений в русском и испанском языках и их сопоставительный анализ. В рамках статьи мы попытаемся ответить на следующие вопросы:

- какие значения могут выражать инфинитивные предложения в русском и испанском языках;

- каковы структурные особенности этих предложений в русском и испанском языках;

- какие лингвистические маркеры позволяют определить семантику данных конструкций;

- какие структурно-семантические соответствия изучаемых явлений наблюдаются в русском и испанском языках.

Как было сказано выше, инфинитивные предложения выражают значение волеизъявления, в связи с чем необходимо определить их место в системе побудительных предложений, назначением которых является побуждение адресата речи к совершению какого-либо действия [9, с. 222].

Общепризнанными видами побуждения являются приказ, просьба, совет, запрещение. Одним из формальных критериев их разграничения является интонация, на что указал еще А. М. Пешковский: «...мы должны отметить, что специальные оттенки создаются в нем (повелительном наклонении $-B . K$.) исключительно интонационными средствами. Собственного говоря, формы иди, идите и т. д., взятые вне интонации, равно способны выражать и приказ, и просьбу, и совет, и т. д. и, следовательно, не выражают ничего этого, а лишь простое побуждение к действию...» [10, с. 207].

В отечественной лингвистике в инфинитивных предложениях выделяют, прежде всего, значение приказа или запрещения (см., например, $[1 ; 2 ; 5$; 13-15]). Значение приказа обычно реализуется в утвердительных предложениях, а значение запрещения - в отрицательных. Ученые также указывают на большую степень категоричности инфинитива по сравнению с глаголами повелительного наклонения специализированным средством выражения побужде- ния. Инфинитив означает, по словам В. В. Виноградова, «безапелляционный приказ, категорическое постановление, распоряжение» [15, с. 490] (о лингвистических причинах категоричности инфинитива см.: [7]).

В русском языке, как и в испанском, подобная категоричность, безапелляционность приказа или запрещения присуща восклицательным предложениям. Например: Молчать! (1) Прекратить! (2)

В приведенных примерах инфинитивных предложений, несмотря на то, что они являются утвердительными, выражается значение запрещения, поскольку речь идет о побуждении не к реализации выраженного инфинитивом действия, а к его прекращению. В одних случаях значение запрещения эксплицировано (пример 2), в других оно формально не выражено и вытекает из семантики глагола (пример 1). Ср.:

Молчать! = Не разговаривать! = Прекратить разговоры! (3)

Замена инфинитива в наших примерах на глагол повелительного наклонения при сохранении коммуникативного (восклицательного) типа предложения ведет к снижению категоричности побуждения. Ср.:

Молчать! (1) и Молчи (mе)! (4)

Прекратить! (2) и Прекрати(те)! (5)

Считается, что для выражения значений приказа или запрещения как категоричных видов побуждения достаточно минимального контекста - только сам инфинитив при наличии соответствующей восклицательной интонации, что, на первый взгляд, подтверждают приведенные выше примеры $(1,2)$. Однако так происходит далеко не всегда. Рассмотрим в качестве примера следующий отрывок из повести М. Булгакова «Собачье сердце»:

- Шарику ничего не давать! - загремела команда из смотровой. (6)

- Усмотришь за ним, как же.

- Запереть! (7)

В приведенном отрывке инфинитивные предложения существенно различаются. Во-первых, они выражают разные виды побуждения - запрещение (6) и приказ (7). Во-вторых, эти значения реализуются соответственно в отрицательной и утвердительной конструкции. В-третьих, инфинитивные предложения отличаются степенью развернутости своей структуры.

Последнее положение принципиально важно, поскольку оно позволяет определить правомерность утверждения о минимальной структуре инфинитивного предложения (см., например, [5]). С этой целью сравним примеры $(1,2,6$ и 7) и попытаемся ответить на вопрос, почему в одних случаях исследуемые нами конструкции представлены одним только инфинитивом $(1,2,7)$, а в других наряду с главным членом 
предложения - инфинитивом - присутствуют и другие второстепенные члены.

В предложении Шарику ничего не давать! (6) наличие дополнений обусловлено обязательной валентностью глагола давать - давать кому что. В случае их отсутствия предложение без опоры на предшествующий контекст и/или коммуникативную ситуацию становится семантически недостаточным. Сp.:

Шарику ничего не давать! и *Не давать! (8)

Аналогичными причинами вызвано употребление второстепенных членов предложения и в следующих примерах:

Убрать эту пакость с шеи... (9)

Кто это тут вам папаша? Называть меня по имени и отчеству! (10)

В этих предложениях также реализуются валентности соответствующих глаголов: убрать что откуда, называть кого как, каждая из которых, будучи представлена определенной словоформой, является членом предложения. При их отсутствии инфинитивное предложение становится семантически неполным, а потому непонятным. Ср.:

Убрать эту пакость с шеи... (9) и *Убрать! (11)

Называть меня по имени и отчеству! (10) и * Называть! (12)

Тем не менее обязательная валентность глагола далеко не всегда реализуется в предложении. В частности, так происходит при использовании словоформ, зависимых от инфинитива, не в структуре предложения, а в предшествующем ему контексте, благодаря чему инфинитив выражает категорическое волеизъявление (приказ или запрещение). Ср.:

Убрать эту пакость с шеи... (9) и Что это за пакость у вас на шее? Убрать! (13)

В случаях такого рода правомерно говорить о расчлененной структуре инфинитивного предложения, в котором второстепенные члены находятся в препозиции относительно главного члена предложения - инфинитива, что возможно далеко не всегда. Cp.:

Кто это тут вам папаша? Называть меня по имени и отчеству! (10) и Я вам не папаша. У меня есть имя и отчество. *Называть! (14)

Сравним приведенные ранее примеры однословных инфинитивных предложений.

Молчать! (1) Прекратить! (2) Запереть! (7)

Эти предложения лишь на первый взгляд кажутся одинаковыми с точки зрения их формальной организации. На самом деле в их основе лежат две разные структуры. В примере (1) предложение семантически самодостаточно. Значение запрещения определенного действия осуществляется в нем путем замены обозначения этого действия его антонимом: Молчать! (1) = Не разговаривать! (3)
В примере (2) реализуется значение запрещения на продолжение действия, как правило, нежелательного с точки зрения говорящего, что уже предполагает экспликацию этого действия:

Прекратить! (2) = Прекратить делать что! (15)

Если это действие формально не выражено, оно однозначно извлекается из контекста. Ср.:

Что вы разговариваете / смеетесь / балуетесь? Прекратить! = Прекратить разговаривать / смеяться / баловаться! (16)

Вместо инфинитивной формы второго глагола возможно использование образованных от них акциональных имен. Ср.:

Прекратить разговаривать / смеяться / баловаться! (16) и Прекратить разговор(ы) / смех / баловство! (17)

Точно также неэксплицированный объект действия в примере (7) при переходном инфинитиве запереть кого / что определяется предшествующим контекстом и не требует его специальной вербализации. Таким образом, инфинитивные предложения в примерах 2 и 7 имеют усеченную эллиптическую конструкцию. Эллипсис же, как известно, - отличительная черта устной речи.

Эллиптичными могут быть не только второстепенные члены предложения в виде словоформ и словосочетаний, как в примере (7), но и полнозначные глаголы в форме инфинитива (13), которые также являются распространителями инфинитива. В сочетании с главным членом - инфинитивом - они образуют перифразы, сходные по своей семантике с лексико-грамматической группой глаголов финитного способа действия.

Рассмотрим теперь, кому может быть адресовано волеизъявление в инфинитивном предложении и находит ли это отражение в его структуре. Мнение А. А. Шахматова на этот счет весьма определенно и категорично: «...рассмотрение всех случаев, где в безличном предложении главным членом является инфинитив, убеждает, что всюду инфинитив дополнен или может быть дополнен указанием на производителя действия» [2, с. 108]. Правда, он все же отмечает случаи, когда инфинитив дополнить указанием на лицо невозможно [Там же, с. 104]. Аналогичную точку зрения высказывает и А. М. Пешковский. Он, в частности, отмечает глагольный характер главного члена - инфинитива, и «...потому, - пишет он, - имеется, как норма, и член, обозначающий д е я т е л я. Член этот - д а т е л ь н ы й падеж существительного при инфинитиве» [10, с. 381].

Если исходить только из специализированных средств выражения побуждения - глаголов повелительного наклонения, то ответ на поставленный вопрос довольно прост: в русском языке глаголы повелительного наклонения имеют только формы ед. и 
мн. числа, а выражаемое ими побуждение относится к собеседнику. Данным обстоятельством, собственно, и объясняется тот факт, что в силу очевидности субъекта потенциального действия - адресата волеизъявления - он, как правило, не находит эксплицитного выражения в предложении. Использование же личных местоимений при глаголах повелительного наклонения, как отмечал академик В. В. Виноградов, вызывает определенный стилистический эффект, они модифицируют значение побуждения - усиливают или снижают степень его категоричности в зависимости от занимаемого ими места в структуре предложения - препозитивного или постпозитивного относительно глагола-сказуемого. «...личные местоимения, присоединяясь к формам повелительного наклонения, выражают различия в их экспрессивных оттенках. Именно: присоединяясь спереди к форме повелительного наклонения, они усиливают категоричность приказания, совета, побуждения; присоединяясь сзади (если нет оттенка заклинания, брани или пожелания), смягчают тон приказания» [15, c. 484].

Однако побуждение может относиться не только к собеседнику - 2-му лицу ед. и мн. числа, но и к группе лиц, включая говорящего, т. е. к 1-му лицу мн. числа, а также к 3-му лицу ед. и мн. числа - неучастнику/неучастникам коммуникации. Смена адресата влечет за собой смену средств выражения побуждения. Глаголы изъявительного наклонения 1-го лица мн. числа (с частицей давай или без нее) указывают на приглашение к совместному действию), глаголы изъявительного наклонения 3-го лица ед. и мн. числа с частицей nусть адресуют побуждение неучастнику коммуникации. Ср.:

Помолчи! (ты) и Помолчите! (Вы, ты + ты, вы + вы) (18)

Помолчим! / Давайте помолчим! (мы) (19)

Пусть помолчит (он /она) (20)

Пусть помолчат (они)! (21)

Очевидно, под влиянием форм императива в глагольных предложениях, в которых побуждение адресовано участникам коммуникации, в том числе и самому говорящему, субъект потенциального действия, как правило, не эксплицируется. Его репрезентация вызвана следующими факторами.

Во-первых, актуализацией семантики формы глагола изъявительного наклонения 1-го лица мн. числа с частицей давай - приглашением к совместному действию, что обычно осуществляется сочетанием местоимения мы с другими лексемами - мы все, все вместе, мы все вместе:

Давайте мы / мы все / все вместе / мы все вместе споем эту песню. (22)

Во-вторых, необходимостью номинации адресата в случае выражения побуждения 3-му лицу.
Таким образом, репрезентация адресата в побудительных предложениях может быть факультативной и обязательной. Она является факультативной во всех типах предложений, в которых побуждение касается участников коммуникации, а именно в глагольных предложениях с формами повелительного наклонения, с глаголами изъявительного наклонения 1-го лица мн. числа, а также в инфинитивных предложениях. И наоборот, репрезентация адресата - субъекта потенциального действия обязательна, если побуждение относится к неучастнику коммуникации.

Возможно и другое объяснение такому положению дел. Вполне правомерно, на наш взгляд, различать прямое побуждение, адресованное участникам коммуникации, главным образом собеседнику, и опосредованное, в котором две пропозиции и два разных субъекта: один из них формальный адресат - участник коммуникации, а другой - потенциальный адресат, который, не будучи участником коммуникации, должен осуществить предлагаемое говорящим действие. Ср.:

Что этот дуралей бормочет? ... Позвать Тредиаковского! (23)

Позвать Тредиаковского! (23) = Скажите, чтобь пришел Тредиаковский. (24)

Тем не менее ставить знак равенства между имплицитным адресатом в разных типах предложения нельзя. В частности, в предложениях с глаголами повелительного наклонения формально не выраженный субъект является более определенным, чем в инфинитивных предложениях. Ср.:

Молчи! (25), Молчите! (26) и Молчать! (1)

Однако и в глагольных предложениях статус адресата и характер отношений коммуникантов не всегда очевидны. Адресат является достаточно определенным лишь в случае употребления глагола повелительного наклонения в форме ед. числа, которая однозначно указывает и на количество адресатов (один), и на степень близости коммуникантов (о чем сигнализирует обращение к адресату на $\mathrm{mbl}$ ). При этом отношения коммуникантов менее определенные. Они могут быть как симметричными (друг говорит другу), так и несимметричными (старший младшему, начальник подчиненному и т. п.). Глагол повелительного наклонения в форме мн. числа нейтрализует указанные выше характеристики коммуникантов. Как и местоимение $в b l$, эта форма может означать обращение либо к одному собеседнику на $b b l$, либо к нескольким собеседникам на $m b l$ или на $в b l$. Фактически отношения коммуникантов также никак не маркируются глагольной формой повелительного наклонения и могут быть и симметричными, и несимметричными. Контекст, как правило, снимает подобную неопределенность глагольной формы, однако принципиально важно то, что в предложении с глаголом повелитель- 
ного наклонения многие параметры адресата, как, впрочем, и адресанта, не имеют формального выражения. Из всего диапазона возможных статусно-ролевых отношений коммуникантов в предложениях такого рода маркированной является лишь форма $m b l$-обращения к одному адресату, которая может быть противопоставлена опять-таки либо одному адресату, либо нескольким, которые могут иметь или равный социальный статус, или более низкий.

В инфинитивных же предложениях и те немногие различия в представлении коммуникантов, которые отмечены в предложениях с глаголом повелительного наклонения в форме ед. числа, не находят формального выражения и полностью исчезают (см. примеры 27-29). Без опоры на коммуникативную ситуацию, на контекст неясно, кому адресовано волеизъявление говорящего - одному лицу или нескольким лицам. Но ясно только одно - безоговорочный приказ или запрещение возможны только в асимметричной коммуникативной ситуации при неравном статусе коммуникантов типа начальник - подчиненный. В этом отношении инфинитивные предложения оказываются более определенными, чем предложения с глаголом повелительного наклонения.

Ученые неоднократно обращали внимание на связь между определенностью/неопределенностью адресата волеизъявления и категоричностью побуждения в инфинитивных предложениях. На этом основании А. А. Шахматов выделял определенно-личные и неопределенно-личные инфинитивные предложения. В определенно-личных предложениях побуждение адресовано 2-му лицу ед. или мн. числа, т. е. одному или нескольким адресатам, причем оно выражает приказание более категорично по сравнению с формой повелительного наклонения. В неопределенно-личных же предложениях приказание адресовано «неопределенным лицам или вообще ко всякому, кого оно касается» [2, с. 81-83]. Эти идеи нашли дальнейшее отражение в трудах отечественных лингвистов. В частности, В. В. Виноградов отмечает способность инфинитива выразить побуждение, адресованное не только одному лицу, но и коллективу, массе, вводя тем самым понятие обобщенного субъекта [15].

Заметим, что имплицитность адресата действия в предложении отнюдь не препятствует его однозначной интерпретации. Ср.:

Убрать эту пакость с шеи... (4)

Кто это тут вам папаша? Называть меня по имени и отчеству! (5)

Что этот дуралей бормочет? ... Позвать Тредиаковского! (23)

Утопить Трезорку! (27)

В примерах 4 и 5 адресатом говорящего является конкретное лицо - Шариков, к которому непосред- ственно обращается профессор Преображенский, тогда как в примерах 23 и 27 адресатом побуждения является неопределенное лицо, кто-то из слуг капризного барина.

В иных коммуникативных условиях инфинитивные предложения зачастую носят обобщенный характер и адресованы неопределенному множеству лиц, как в следующих примерах. Ср.:

Не курить. (28) По газонам не ходить. (29)

Неопределенность же либо обобщенность адресата снижают категоричность волеизъявления. В приведенных примерах запрещение распространяется на всех лиц, которые находятся или могут находиться в каком-то определенном месте, т. е. оно касается как присутствующих, так и отсутствующих лиц, а категорически запрещать что-либо делать отсутствующим вряд ли возможно.

Следует также заметить, что это другой коммуникативный тип предложения - утвердительный, а не восклицательный. В восклицательном же предложении запрещение, как правило, имеет конкретного адресата (либо отдельное лицо, либо группу лиц), хотя он не всегда эксплицирован в предложении.

Наряду с рассмотренными выше примерами, в которых адресат побуждения эксплицитно не выражен, в русском языке достаточно частотны инфинитивные предложения с обязательной репрезентацией субъекта действия в форме дательного падежа (об их семантике и происхождении см. [7]). Они построены по модели кому делать что: (30)

Завтра утром на станиию уезжать пареньку.

Косвенное дополнение в форме дательного падежа может быть выражено не только именем нарицательным, как в приведенном примере, но и именем собственным, а также личным местоимением 1-го, 2-го и 3-го лица ед. и мн. числа. Ср.:

Завтра утром на станичию уезжать мне /тебе/ ему/ ей/ нам /вам /им. (31)

Все эти конструкции имеют значение долженствования и соответствуют личным предложениям, в которых дополнение становится подлежащим, а инфинитив - финитной формой глагола (подробнее см. [4, с. $250 ; 9$, с. $114-115 ; 7])$. Ср.:

Вам не видать таких сражений. (32) = Bын не увидите таких сражений (33)

Конструкции, в которых есть косвенные формы личных местоимений 2-го лица ед. и мн. числа, можно выделить в отдельный разряд инфинитивных конструкций и считать их также одним из способов выражения побуждения в русском языке. В отличие от рассмотренных ранее инфинитивных конструкций, которые выражают значение категоричного волеизъявления (приказа или запрещения), конструкции типа тебе / вам делать что указывают на побуждение 
косвенно, путем актуализации модального значения необходимости совершения названного инфинитивом действия. Ср.:

Тебе ходить. (34) - Ты должен ходить. (35) Ходи. (36)

Инфинитив с частицей бы ученые склонны рассматривать как особую разновидность инфинитивных предложений (см., например, [7; 14, с. 170; 15, с. 491]), которые выражают разные модальные значения. Если адресатом является 2-е или 3-е лицо, которое всегда эксплицируется в структуре предложения, то инфинитив выражает значение совета:

Тебе / вам бы отдохнуть. (37)

Ему /ей / им бы отдохнуть. (38)

Совет является некатегоричным видом побуждения, однако в инфинитивном предложении с частицей бы он становится еще более мягким. Ср.:

Тебе бы отдохнуть. (39) и Ты бы отдохнул. (40)

Если же адресатом является сам говорящий, то реализуется значение желательности действия. В случаях такого рода субъект потенциального действия может быть как имплицитным, так и эксплицитным. Таким образом, обязательность/факультативность выражения адресата сигнализирует о разных видах модальности в инфинитивном предложении, а частица бы является маркером некатегоричности побуждения. (42)

Отдохнуть бы! (41) = Мне / нам отдохнуть бы !

Таким образом, главная особенность инфинитивных предложений (отсюда их второе название - дебитивные) в русском языке заключается в том, что в их основе лежит вербально не выраженное значение субъективно устанавливаемой необходимости, которая в конкретных коммуникативных условиях предстает в виде набора семантических вариантов. Основными из них являются значения приказа, запланированности, невозможности, объективной обусловленности, целесообразности и немотивированности, которые тоже могут варьироваться. Так, значение целесообразности нередко реализуется в виде значения совета или желательности, о которых говорилось выше (подробнее см. [1; 4, с. 245-249; 14; 15]). Критерием разграничения этих и других значений инфинитивных предложений могут служить такие факторы, как адресованность 1-му, 2-му или 3-му лицу, обязательная или факультативная эксплицитность адресата, а также наличие/отсутствие частицы бы и соответствующее интонационное оформление.

Перейдем к рассмотрению инфинитивных предложений в испанском языке, которые также могут выражать значение побуждения (см., например, [8; 14; 16-19]). Поскольку в случаях такого рода инфинитив является функциональным субститутом императива, то прежде всего отметим отличия испанских форм повелительного наклонения от русских. В ис- панском языке дифференцируются не только формы ед. и мн. числа, но и форма обращения к собеседнику/ собеседникам на $m b l$ или на $\boldsymbol{b b l}$. Благодаря этому парадигма повелительного наклонения в испанском языке является не двучленной, как в русском языке, а четырехчленной: tú (ты), Usted (вы), vosotros/ vosotras (ты + ты), Ustedes (вы + вы). Отсюда возникает закономерный вопрос: субститутом каких форм императива может быть инфинитив в испанском языке?

Исследователи отмечают, что инфинитив нередко используется, особенно в неформальном регистре, в ситуации повседневного общения, для выражения побуждения вместо формы vosotros / vosotras (см., например, [13; 18-20]). (46)

¡Entrar! (43) ¡Mirar! (44) ¡Salir! (45) ¡No fastidiar!

По мнению С. Хили-и-Гайя, объясняется это тем, что адресат 2-го лица мн. числа является менее определенным, чем адресат 2-го лица ед. числа, и что подобная неопределенность адресата в большей степени согласуется с категориальным значением инфинитива. Другая возможная причина - слабая позиция согласной на конце слова, что может привести к замене одной согласной на другую $(d-r)$ (см. подробнее [13, с. 55]; см. также [3; 14; 17]).

Несмотря на восклицательную интонацию, испанский инфинитив выражает либо нейтральную, либо мягкую форму побуждения. Для выражения безапелляционного приказа одному или нескольким лицам в асимметричной ситуации общения в испанском языке используются формы императива, а не инфинитив, как в русском языке.

Ср.: Молчать! и ¡Cállate! (tú) ¡Cállese! (Usted) ¡Cállaos! (vosotros)

¡Cállense! (Ustedes) (47)

В отрицательных предложениях значение запрета или предостережения более категорично, чем в предложениях с глаголом сослагательного наклонения [21, p. 2339]. Ср.: (49)

¡No fumar, ni gritar! (48) и ¡No fumeis, ni griteis!

Категорический отказ или решительное несогласие с чем-либо выражается отрицательной инфинитивной конструкцией с $n i$ :

¡Ni pensarlo! 'Не вздумай'! (50)

¡Ni soñar! 'И ни мечтай'! (51)

Императивные инфинитивные предложения, которые также выражают приказ или запрещение, но адресованы неопределенному множеству лиц - всем, а не отдельным конкретным лицам, не столь категоричны. Сфера их употребления, как и в русском языке - объявления и плакаты в общественных местах, разного рода инструкции, в том числе инструкции по заполнению бланков. Ср.: 
No fumar. (52) = Не курить. (53)

Firmar y remitir a la dirección indicada. $=$ Подписать и отправить по указанному адресу. (54)

Наряду с однословным инфинитивом в испанском языке есть изосемичная инфинитивная конструкция с предлогом $a$, которая адресована одному или нескольким лицам (tú и vosotros/vosotras при условии обращения к ним на ты [18, p. 2339; 19, p. 81].

¡A dormir! (55) ¡A estudiar! (56) A esperar! (57)

Конструкции такого рода оказывают большее воздействие, чем иные формы выражения приказа или просьбы (см., например, [8, p. 3151; 13, с. 55; 17, p. $401 ; 18$, p. 2339]). Доказательством этого может служить тот факт, что категоричность побуждения в предложении с однословным инфинитивом можно смягчить, добавив вежливое выражение por favor 'пожалуйста', а в предложении а + инфинитив оно не допустимо. Ср.:

¡Comer, por favor! (58) и ¡*A comer, por favor! (59)

Инфинитивные предложения с предлогом $a$ отличаются также тем, что, как уже говорилось, они адресованы не только группе людей, но и одному лицу $[19$, p. $81 ; 20$, p. 2339]. Объединяют же их условия употребления: неформальный регистр общения и близость коммуникантов [20, p. 81].

Кроме значения приказа, конструкции такого рода передают также ярко выраженный призыв (приглашение) к совершению действия, приятного с точки зрения говорящего:

¡A distraerse! Estamos en Carnaval! (60) (цит. по $[8$, p. 3151]).

Данные предложения следует отличать от других, в которых инфинитив также употребляется с предлогом $a$ :

El marido a ganar dinero y ella a despilfarrarlo en trapos (61) (цит. по [19, p. 689]).

Теоретически возможная замена инфинитива на финитный глагол ведет к искажению семантики исходной конструкции:

El marido a ganar dinero y ella a despilfarrarlo en trapos = El marido gana dinero y ella lo despilfarra en trapos. (62)

Как справедливо отмечает М. Мольо, инфинитивная конструкция (61) не изофункциональна конструкции с финитным глаголом (62), поскольку в последней отсутствует модальное значение, а потому ее семантическим эквивалентом является предложение с модальным глаголом долженствования:

El marido debe ganar dinero y ella lo despilfarra en trapos. (63)

Будучи синонимичными, данные конструкции отличаются тем, что в примере с независимым инфинитивом формально не выраженным является однозначно интерпретируемое носителем испанского языка дополнительное значение - значение критиче- ского отношения говорящего к описываемому положению дел.

Следует также отметить тот факт, что конструкции типа ¡A trabajar! и El marido a ganar dinero... омонимичны лишь на первый взгляд. Первая конструкция представлена простым нераспространенным предложением и репрезентирует одну пропозицию, тогда как вторая суть сложносочиненное предложение, в котором противопоставлены две пропозиции, два разных действия и два разных субъекта действия.

Семантическим эквивалентом данных конструкций в русском языке является сложносочиненное предложение с противительным союзом а, в котором, в отличие от испанского языка, употребляется не инфинитив, а транспонированная форма императива. Cp.:

El marido a ganar dinero y ella a despilfarrarlo en trapos $=$

Муж зарабатывай деньги, а она спускает их на тряпки. (64)

К слову сказать, в русском языке есть подобная конструкция, о чем писал В. В. Виноградов [15, p. 491].

Что касается других модальных значений, выражаемых русскими инфинитивными предложениями, то в испанском языке они репрезентируются двусоставными конструкциями с модальными глаголами.

Инфинитив в испанском языке может быть функциональным субститутом не только повелительного наклонения, но и изъявительного наклонения и кондисионала. Наблюдается это в ответных репликах, в которых в зависимости от реализуемой семантики инфинитив может быть фрагментарным или ретроспективным [17, p. 2333], как в примерах:

A. - ¿Y tú qué haces?

- Pues, limpiar un poco. (65) [8, p. 3151].

Лицо деятеля, которым может быть и 2-е, и 3-е лицо, а также время названного инфинитивом действия, однозначно восстанавливаются из контекста, а потому они не эксплицируются. Ср.:

¿Y ella qué hace?

Pues, limpiar un poco. (66)

- ¿Me trajiste el lbro?

- No. Habérmelo dicho. (67)

В примере (67) употреблен перфектный инфинитив в функции кондисионала, а потому он выражает значение необходимости действия, не совершенного в прошлом, и содержит скрытый упрек собеседнику или 3-му лицу.

Обращает на себя внимание тот факт, что в русском языке инфинитив может быть функциональным субститутом повелительного наклонения для выражения практически всех значений побуждения, тогда как в испанском языке его возможности ограничены. 
Отчасти это объясняется тем, что разные виды побуждения, особенно просьба и запрос информации, в испанском языке гораздо чаще репрезентируются не императивом, а другими языковыми средствами (см., например, [20, p. 314]). В целом же в испанском языке для выражения побуждения чаще всего используются косвенные речевые акты, что в свою очередь обусловлено большей значимостью категории вежливости в испанской лингвокультуре (см., например, $[22 ; 23])$. Кроме того, испанский инфинитив может брать на себя функции изъявительного наклонения и кондисионала и выражать реальную и ирреальную модальность.

В заключение отметим, что инфинитивные предложения и в русском, и испанском языках выражают разные виды побуждения. Полными структурно-семантическими эквивалентами в сравниваемых языках, как в случае выражения некатегоричного волеизъявления, они являются довольно редко. Гораздо чаще при внешнем совпадении конструкций они отличаются прагматическими свойствами. Для испанского языка характерно более дифференцированное указание на адресата волеизъявления (как правило, он является определенным), и одни и те же значения побуждения имеют менее категоричный характер по сравнению с русским языком. Употребление инфинитивных предложений в испанском языке ограничено функционально. Они присущи в основном разговорному стилю речи, а некоторые из них имеют определенный ареал распространения.

Русские инфинитивные предложения имеют более широкий диапазон семантического варьирования, они способны выражать всю палитру модальных значений, что находит отражение в их поверхностной структуре, в обязательности/факультативности экспликации субъекта потенциального действия, богатстве интонационного оформления. Имплицитный адресат (субъект) в русском языке часто бывает неопределенным. В русском языке, в отличие от испанского, в инфинитивных конструкциях возможно не только прямое, но и косвенное выражение значения побуждения, в основе которых лежат разные модели предложения. Сфера функционирования русских инфинитивных предложений гораздо шире. Они используются в разных ситуациях общения.

Испанский язык оказывается богаче в другом отношении - в нем появляются варианты - не только независимый инфинитив, но и сочетание инфинитива с предлогом а, которые различаются по своим прагматическим свойствам, по степени категоричности волеизъявления.

Критерием разграничения разных видов побуждения, а также омонимичных конструкций с инфинитивом является контекст в широком смысле слова, структурные особенности инфинитивного предложе- ния, наличие в нем обязательных и факультативных компонентов и, конечно же, интонация.

\section{ЛИТЕРАТУРА}

1. Тимофеев $K$. $A$. Об основных типах инфинитивных предложений в современном русском литературном языке // Вопросы синтаксиса современного русского языка : сб. ст. / под ред. В. В. Виноградова. М., 1950. C. 257-301.

2. Шахматов A. А. Синтаксис современного русского языка. М. : УРСС, 2001.

3. Martínez Amador E. M. Diccionario Gramatical y de dudas del idioma. Barcelona : Editorial Ramón Sopena, S.A., 1985. $704 \mathrm{p}$.

4. Ломов А. М. Типология русского предложения. Воронеж : Изд-во ВГУ, 1994. 280 с.

5. Русская грамматика. Т. II. М. : Наука, 1980.714 с.

6. Скобликова E. C. Современный русский язык. Синтаксис простого предложения. М. : Высш. школа, 1979. $114 \mathrm{c}$.

7. Кретов А. А. Русские надлично-дебитивные предложения // Сборник статей по языкознанию. К 70-летию профессора В. В. Щеулина. Ч. ІІ. Липецк : ЛГПИ, 1997. С. 84-91.

8. RAE. Nueva Gramática de la Lengua Española. Madrid : Editorial Espasa Calpe, S.A., 2009. 3352 p.

9. Ломов А. М. Русский синтаксис в алфавитном порядке : понятийный словарь-справочник. Воронеж : Изд-во Воронеж. гос. ун-та, 2004. 400 с.

10. Пешковский А. М. Русский синтаксис в научном освещении. 7-е изд. М. : Изд-во Мин-ва Просвещения РСФСР, 1956. $511 \mathrm{c}$

11. Цейтлин С. Н. Необходимость // Теория функциональной грамматики. Темпоральность. Модальность. Ленинград : Наука, 1990. С. 142-156.

12. Галкина-Федорук Е. М. Безличные предложения в современном русском языке. М. : МГУ, 1958.

13. Gili y Gaya S. Curso superior de sintaxis española. Barcelona : Editorial Bibliograf, S.A., 1967. 347 p.

14. Валгина Н. С. Современный русский язык : синтаксис. 4-е изд., испр. М. : Высш. шк., 2003. 416 с.

15. Виноградов В. В. Русский язык : грамматическое учение о слове. 4-е изд. М. : Рус. яз., 2001. 720 с.

16. Alarcos Llorach $E$. Estudios de gramática funcional del español. Madrid : Gredos, 1982.

17. Matte Bon F. Gramática Comunicativa del Español. Tomo 1. Madrid : Edelsa, S.A., 2002. 386 p.

18. Hernanz M. Ll. El infinitivo // Gramática Descriptiva de la Lengua Española. En 3 vol. Dirigida por Ignacio Bosque y Violeta Demonte. Preámbulo de F. Lázaro Carreter. V. 2. Madrid : Espasa Calpe, S.A., 2000. Pp. $2197-$ 2356.

19. Molho M. Sistemática del verbo español. Madrid : Gredos, 1975. 779 p.

20. Matte Bon F. Gramática Comunicativa del Español. Tomo 2. Madrid : Edelsa, S.A., 2003. 369 p.

21. Hernanz M. Ll. El infinitivo en español. Belaterra, $1982.345 \mathrm{p}$. 
22. Корнева В. В. Косвенные речевые акты совета в испанском и русском языках // Германские, романские и русский язык в сопоставительном аспекте : сб. науч. ст. Воронеж : ВГУ, 1998. С. 102-110.

23. Корнева В. В. Выражение категоричного волеизъявления в русском и испанском языках // Актуальные проблемы сопоставительного изучения германских, романских и славянских языков : тез. докл. науч. конф. Воронеж : ВГУ, 1998. С. 65-66.

\section{ИСТОЧНИКИ}

1. Булгаков М. Повести и рассказы. М. : Худож. лит., 1985. $222 \mathrm{c}$

2. Салтыков-Щедрин М. Е. Избранные рассказы. М. : Худож. лит., 1975. 234 с.

\section{REFERENCES}

1. Timofeev K. A. Ob osnovnykh tipakh infinitivnykh predlozhenij v sovremennom russkom literaturnom yazyke [On basic types of infinitive sentences in the modern Russian language]. In Voprosy sintaksisa sovremennogo russkogo yazyka: Sb. statej / Pod red. V. V. Vinogradova. M., 1950. Pp. 257-301.

2. Shakhmatov A. A. Sintaksis sovremennogo russkogo yazyka. M. : URSS, 2001. $621 \mathrm{~s}$.

3. Martínez Amador Emilio M. Diccionario Gramatical y de dudas del idioma. Barcelona: Editorial Ramón Sopena, S.A., 1985. 704 p.

4. Lomov A. M. Tipologiya russkogo predlozheniya [The typology of Russian sentence]. Voronezh: Izd-vo VGU, 1994. 280 p.

5. Russkaya grammatika [Russian Grammar]. Vol. II. Moskva: Nauka, 1980. 714 s.

6. Skoblikova E. S. Sovremennyj russkij yazyk. Sintaksis prostogo predlozheniya [The modern Russian language. Syntax of the simple sentence]. Moscow: Vyssh. shkola, 1979. 114 p.

7. Kretov A. A. Russkie nadlichno-debitivniye predlozheniya [Russian spurapersonal debitive sentences]. In Sbornik statej po yazikoznaniyu. K 70-letiyu professora V.V. Shcheulina [Festschrift for 70th anniversary of Prof. V.V. Shcheulin] Ch. II. Lipetchk: LGPI, 1997. Pp. 84-91.

8. RAE. Nueva Gramática de la Lengua Española. Madrid: Editorial Espasa Calpe, S.A., 2009. 3885 p.

9. Lomov A. M. Russkij sintaksis v alfavitnom poryadke: Ponyatijnyj slovar'-spravochnik [Russian syntaz from A to Z: A Dictionary of basic concepts]. Voronezh: Izd-vo Voronezh. gos. un-ta, 2004. 400 s.

10. Peshkovskij A. M. Russkij sintaksis v nauchnom osveshhenii [Russian syntax from the academic perspective]. 7th ed. Moscow: Izd-vo min-va Prosveshheniya RSFSR, 1956. $511 \mathrm{~s}$.
11. Tsejtlin S. N. Neobkhodimost' [Necessity]. In Teoriya funktsional'noj grammatiki. Temporal'nost'. Modal'nost' [Functional grammar theory. Temporality. Modality]. Leningrad: Nauka, 1990. Pp. 142-156.

12. Galkina-Fedoruk E. M. Bezlichnye predlozheniya v sovremennom russkom yazyke [Impersonal sentences in the Russian language]. Moscow: MGU, 1958.

13. Gili y Gaya S. Curso superior de sintaxis española. Barcelona: Editorial Bibliograf, S.A., 1967. 347 p.

14. Valgina N. S. Sovremennij russkij yazyk: Sintaksis [Modern Russian: Syntax]. 4-e izd., ispr. Moscow: Vyssh. shk Sovremennyj russkij., 2003. 416 s.

15. Vinogradov V. V. Russkij yazyk: grammaticheskoe uchenie o slove [The Russian Language. Grammatical theory of a Word]. 4-e izd. Moscow: Rus. yaz., 2001. $720 \mathrm{p}$.

16. Alarcos Llorach E. Estudios de gramática funcional del español. Madrid: Gredos, 1982.

17. Matte Bon F. Gramática Comunicativa del Español. Tomo 1. Madrid: Edelsa, S.A., 2002. 386 p.

18. Hernanz M. L1. El infinitivo. In Gramática Descriptiva de la Lengua Española. En 3 vol. Dirigida por Ignacio Bosque y Violeta Demonte. Preámbulo de F. Lázaro Carreter. V. 2. Madrid: Espasa Calpe, S.A., 2000. Pp. 2197-2356.

19. Molho M. Sistemática del verbo español. Madrid: Gredos, 1975. 779 p.

20. Matte Bon F. Gramática Comunicativa del Español. Tomo 2. Madrid: Edelsa, S.A., 2003. 369 p.

21. Hernanz Ll. M. El infinitivo en español. Belaterra, $1982.345 \mathrm{p}$.

22. Korneva V. V. Kosvennye rechevye akty soveta $\mathrm{v}$ ispanskom i russkom yazykakh [Implicit speech acts in the Spanish and Russian languages]. In Germanskie, romanskie $i$ russkij yazyk $v$ sopostavitelnom aspekte [Germanic, Romance and the Russian Languages in Comparison and Contrast]. Voronezh, 1998. Pp. 102110.

23. Korneva V. V. Vyrazhenie kategorichnogo voleiz»yavleniya v russkom i ispanskom yazykakh [Expression of adamant stated wish in the Russian and Spanish Languages]. In Aktual'nye problemy sopostavitel'nogo izucheniya germanskikh, romanskikh i slavyanskikh yazykov: tezisy dokladov nauchnoj konferentsii. Voronezh: VGU, 1998. Pp. 65-66.

\section{SOURCES}

1. Bulgakov M. Povesti i rasskazy [Novels and Stories]. Moskva: Khud. lit-ra, 1985. 222 p.

2. Saltykov-Shchedrin M. E. Izbrannye rasskazy [Selected Stories]. Moskva: Khud. lit-ra, 1975. 234 p. 
Воронежский государственный университет Корнева В.В., доктор филологических наук, профессор, заведуюшая кафедрой романской филологии

E-mail: kornevavalentina@mail.ru

Поступила в редакиию 25 ноября 2019 г.

Принята к публикаџии 27 декабря 2019 г.

Для цитирования:

Корнева В. В. Инфинитивные предложения в русском и испанском языках // Вестник Воронежского государственного университета. Серия: Лингвистика и межкультурная коммуникация. 2020. № 1. С. 51-60. DOI: https://doi.org/10.17308/lic.2020.1/2730
Voronezh State University

Korneva V. V., Doctor of Philology, Professor, Head of the Romance Philology Department

E-mail: kornevavalentina@mail.ru

Received: 25 November 2019

Accepted: 27 December 2019

\section{For citation:}

Korneva $V . V$. Infinitive sentences in the Russian and Spanish languages. Proceedings of Voronezh State University. Series: Linguistics and Intercultural Communication. 2020. No. 1. Pp. 51-60. DOI: https://doi.org/10.17308/ lic. $2020.1 / 2730$ 